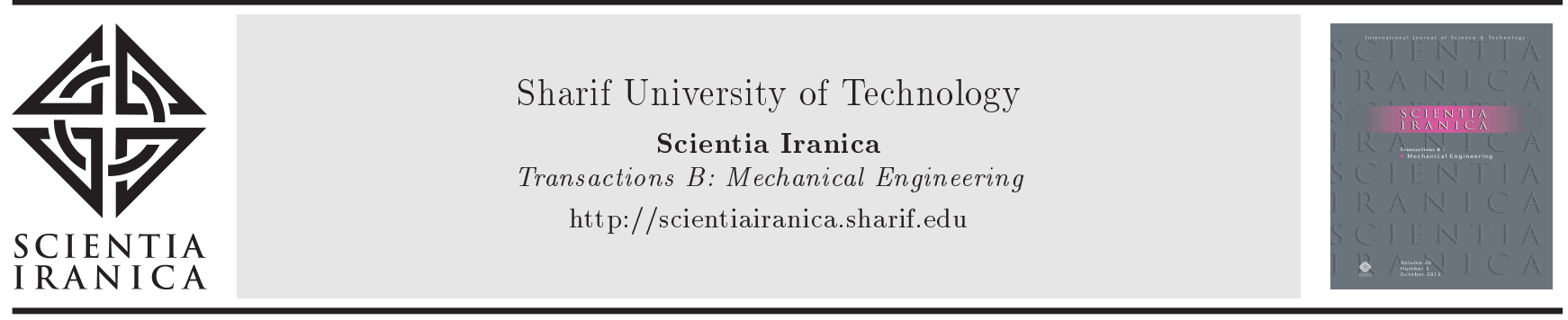

\title{
Vibro-acoustic analysis of laminated composite plate structure using structure-dependent radiation modes: An experimental validation
}

\author{
N. Sharma ${ }^{a}$, T. Ranjan Mahapatra ${ }^{a, *}$, and S. Kumar Panda ${ }^{b}$ \\ a. School of Mechanical Engineering, KIIT University, Bhubaneswar: 751024, Odisha, India. \\ b. Department of Mechanical Engineering, NIT, Rourkela: 769008, Odisha, India.
}

Received 20 April 2017; received in revised form 21 June 2017; accepted 18 Sep 2017

\author{
KEYWORDS \\ Laminated composite \\ plate; \\ Modal analysis; \\ Acoustic radiation; \\ Radiation efficiency; \\ Sound power; \\ Experimental \\ vibration.
}

\begin{abstract}
In this article, the acoustic radiation responses of the layered composite flat panel in an infinite rigid baffle under the influence of harmonic point load and various support conditions were investigated numerically. The laminated composite flat panel responses were computed using the ANSYS parametric design language code. The natural frequencies obtained using the current simulation model matched the earlier published values as well as in-house experimental results. The eigenvectors corresponding to the validated eigenvalues were extracted and utilised for the computation of the acoustic properties numerically by solving through Rayleigh integral scheme. The first radiation mode's amplitudes for the vibrating plate were computed and validated with the results available in open literature. Further, the self-radiation efficiency and radiated sound power were obtained based on the structure-dependent radiation modes, and all the radiation modes were also included to evaluate the exact radiated sound power. Finally, the effects of different composite (carbon/epoxy and glass/epoxy) properties, constraint conditions, and location of point load on the displacement and velocity responses, radiation efficiency, and radiated acoustic power level of the layered flat panel were investigated and discussed in detail.
\end{abstract}

(C) 2018 Sharif University of Technology. All rights reserved.

\section{Introduction}

The present day high-performance industries are constantly striving for the development of lightweight materials, which may reduce substantial fuel consumption without compromising the structural strength and integrity. In this regard, the laminated composite structures have created their own space within the modern

*. Corresponding author. Tel.: +91-9861425597;

E-mail addresses: nits.iiit@gmail.com (N. Sharma);

truptiranjan01@gmail.com; trmahapatra_pe@vssut.ac.in (T.

Ranjan Mahapatra); call2subrat@gmail.com;

pandask@nitrkl.ac.in (S. KumarPanda). engineering domains, such as aerospace, automotive, railway, and marine, due to their excellent specific strength and stiffness properties. However, the weight reduction strategies may also lead to increased noise and vibration levels in the structures and/or structural components specifically, when they are exposed to the intense dynamic loading. In such a situation, the coupling between the vibration and acoustic phenomena plays a vital role in designing structures of specific applications where the minimization of sound radiation is the top priority. Thus, the acoustic radiation behavior of vibrating structures has been an area of extreme interest to researchers for several years. In general, the radiation efficiency and output sound power level have been investigated to show the acoustic behavior 
of the vibrating structures. However, discretization of the Helmholtz's wave equation and its solution for the appropriate boundary conditions form the basis of the acoustic response analysis of the structures. Cunefare et al. [1-3] developed and subsequently applied the modal techniques to investigate the exterior radiation problems. It was demonstrated that the eigenvalue decomposition of a discrete representation for the radiated power (as obtained using Rayleigh's integral) yields a modal representation known as acoustic radiation modes. These radiation modes depend solely on the wavenumber and external surface geometry of a radiating structure $[4,5]$. However, the location and size of the mass loading have a significant effect on the acoustic radiation of the structures [6]. It is also noticed that the far-field sound radiation of the laminated composite flat panel is greatly affected by the lamination schemes $[7,8]$. In general, the structuredependent radiation modes are more desirable than the conventional acoustic radiation modes, because the former one basically corresponds to the effect of the dynamic properties (boundary conditions, material properties) of the structures on the acoustic power radiation [9]. Therefore, the frequency responses require to be managed properly for structures made of composite materials, whose physical properties are significantly dependent on the orientation of fibres (lamination scheme), and affect the vibration and acoustic responses.

The sound radiation characteristic of the baffled flat panel is usually considered the benchmark for the investigation of sound radiated by the intricate structures [10]. The numerical and analytical solutions for the sound radiation resistances have been reported in the past for the arbitrary wavenumbers instead of the widely accepted numerical integration technique [11]. However, most of the studies are based on the selfradiation resistances only. This is because the mutual radiation resistances resulting from the cross-modal coupling have an insignificant impact on the sound power radiation. It is also believed that the consideration of the mutual radiation resistances can also result in an enormous computational burden. However, the mutual radiation resistances cannot be ignored for estimating sound power in a broad frequency range, especially when the structures are loaded with masses [12]. Over the last few decades, the Finite-Element Method (FEM) has proved to be a versatile numerical tool and widely appreciated by the scientific community for its complex structural analysis. Moreover, with the aim of accurately modelling the mid-plane kinematics of the laminated structure mathematically, various classical, shear deformation, and refined theories were employed in the past [13]. Various advanced (hyperbolic, sinusoidal) shear and normal deformation theories were also used to study the bending and free vibration of laminated composite, Functionally Graded (FG) and sandwich structures [14-20]. The stretching effect was included for the flexural analysis of sandwich composite plates [21,22]. Wu and Huang [23] used layer-wise FEM to study the vibration behaviour of the laminated composite plate and evaluated the acoustic radiation mode amplitudes via the Rayleigh's integral scheme. Chandra et al. [24] performed the vibration analysis of the functionally graded plate using the First-order Shear Deformation Theory (FSDT) followed by the acoustic response analysis through Rayleigh's integral. In addition, it was noted that some coupled FEM-BEM (boundary element method) approach was employed to investigate the vibration and acoustic characteristics of the laminated composite plates [25-28]. In these studies, FEM was used to obtain free vibration responses, while the BEM was employed to predict the sound radiation characteristics. It was observed that the amplitude of the vibration and the acoustic responses are significantly affected by the changes in the mode shapes as well as the excitation location. Zhao et al. [29] obtained analytical solutions for the vibration and sound radiation characteristics of a laminated composite flat panel subjected to moisture load using Rayleigh's integral. In addition, they provided numerical solutions for far-field sound pressure level using the FEM-BEM approach. Au et al. [30] investigated the acoustic responses of the rectangular orthotropic plate vibrating under the action of transient moving loads with the help of Rayleigh's integral in the time domain. Later, an FE model based on the FSDT was introduced by Arunkumar et al. [31] to study vibroacoustic characteristics of sandwich aerospace panels using Rayleigh's integral.

A brief, yet essential, review of the literature reveals that although the radiation mode theory is well developed, it has mostly been applied to study the acoustic behaviour of isotropic structures. Studies related to the acoustic radiation behaviour of the laminated composite structures based on the radiation mode theory are very limited. It is also understood that the structure-dependent radiation modes should be considered for the accurate prediction of the vibroacoustic behaviour of any structure as they provide a far better insight than the acoustic radiation modes do. However, the structure-dependent radiation modes are directly affected by the choice of the theory used to analyse the vibration behaviour. In this paper, the authors attempted to investigate the sound radiation characteristics of the vibrating laminated composite plate in an infinite rigid baffle by incorporating the structure-dependent radiation modes. The layered composite flat panel model has been developed in the framework of the FSDT as in ANSYS. Further, the eigen-frequencies obtained using the current model are validated through a comparison with the available 
numerical results as well as the in-house experimental responses. The first radiation mode's amplitudes are obtained using Rayleigh's integral scheme, compared with those published in open literature. In this analysis, two different types of materials have been considered, namely Carbon Fiber Reinforced Plastic (CFRP) and Glass Fiber Reinforced Plastic (GFRP) composite plates with various fiber orientation angles and two support conditions (all sides are simply supported and clamped). In each case, the central and eccentric harmonic point loading cases are considered to obtain the acoustic responses. The numerical results of the selfradiation efficiencies corresponding to different modes, coupled and uncoupled radiated sound powers are obtained using structure-dependent radiation modes, and necessary implications are discussed in detail.

\section{Mathematical modelling}

\subsection{Structural modelling}

Figure 1 depicts the lamination scheme and geometry of the layered flat panel analysed in this work. The panel is modelled in ANSYS, and the analysis is carried out by a simulation model implemented using APDL code. Shell 181, a four-node quadrilateral element, is selected from ANSYS element library to discretise the domain. The element has six degrees of freedom per node. The following displacement equation based on the FSDT [13] is adopted:

$$
\begin{aligned}
& \bar{u}(x, y, z, t)=\mu_{0}(x, y)+z \eta_{x}(x, y), \\
& \bar{\nu}(x, y, z, t)=\gamma_{0}(x, y)+z \eta_{y}(x, y), \\
& \bar{w}(x, y, z, t)=\zeta_{0}(x, y)+z \eta_{z}(x, y),
\end{aligned}
$$

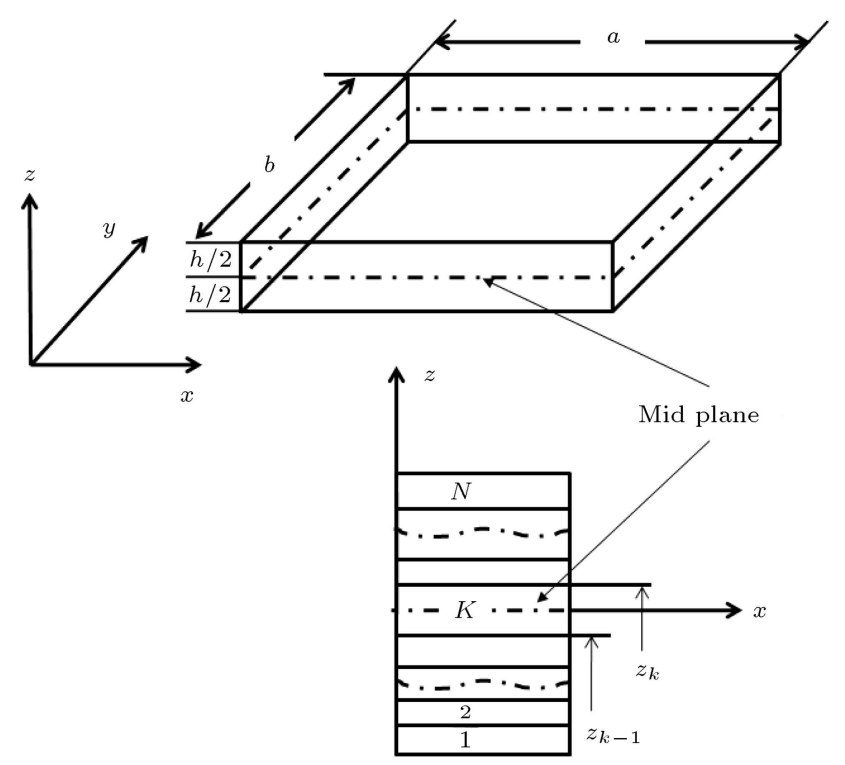

Figure 1. Geometry and lay-up of laminated composite plate. where, $t$ is the time, $\bar{u}, \bar{\nu}$, and $\bar{w}$ are the displacements of any point along $x, y$, and $z$ coordinate axes, respectively. $\mu_{0}, \gamma_{0}$, and $\zeta_{0}$ are the corresponding displacements of a point on the mid plane; $\eta_{x}$ and $\eta_{y}$ are the rotations of normal to the mid-surface $(z=0)$ about $y$ and $x$ axes, respectively; $\eta_{z}$ is the higher order term in the Taylor series expansion which accounts for the linear variation of displacement function along the thickness direction.

The constitutive equation of generalised stress tensor for ( $k$ th) composite lamina oriented at an arbitrary angle ' $\theta$ ' about any arbitrary axes is given by (considering plane stress condition):

$$
\left\{\sigma_{i j}\right\}=\left[\bar{Q}_{i j}\right]\left\{\varepsilon_{i j}\right\},
$$

where $\left\{\sigma_{i j}\right\}=\left\{\begin{array}{lllll}\sigma_{x x} & \sigma_{y y} & \tau_{x y} & \tau_{z x} & \tau_{y z}\end{array}\right.$ and $\left\{\varepsilon_{i j}\right\}=$ $\left\{\begin{array}{lllll}\varepsilon_{x x} & \varepsilon_{y y} & \gamma_{x y} & \gamma_{z x} & \gamma_{y z}\end{array}\right\}$ are the stress and strain tensors for the $k$ th layer, respectively;

$$
\left[\bar{Q}_{i j}\right]=\left[\begin{array}{cccccc}
Q_{11} & Q_{12} & Q_{13} & Q_{14} & 0 & 0 \\
Q_{12} & Q_{22} & Q_{23} & Q_{24} & 0 & 0 \\
Q_{13} & Q_{23} & Q_{33} & Q_{34} & 0 & 0 \\
Q_{14} & Q_{24} & Q_{34} & Q_{44} & 0 & 0 \\
0 & 0 & 0 & 0 & Q_{55} & Q_{56} \\
0 & 0 & 0 & 0 & Q_{56} & Q_{66}
\end{array}\right]
$$

is the transferred reduced stiffness matrix with:

$$
\begin{aligned}
& Q_{11}=\frac{E_{11}}{1-\nu_{12} \nu_{21}}, \quad Q_{12}=\frac{\nu_{12} E_{22}}{1-\nu_{12} \nu_{21}} \\
& Q_{22}=\frac{E_{22}}{1-\nu_{12} \nu_{21}}, \quad Q_{66}=G_{12}, \\
& Q_{44}=G_{13}, \quad Q_{55}=G_{23} .
\end{aligned}
$$

Now, by using the present displacement field (Eq. (1)), the strain matrix for the layered composite plate can be expressed as follows:

$$
\begin{aligned}
& \{\varepsilon\}=\left\{\begin{array}{lllll}
\varepsilon_{x x} & \varepsilon_{y y} & \varepsilon_{x y} & \varepsilon_{x z} & \varepsilon_{y z}
\end{array}\right\}^{T} \\
& =\left\{\left(\frac{\partial \bar{u}}{\partial x}\right)\left(\frac{\partial \bar{\nu}}{\partial y}\right)\left(\frac{\partial \bar{u}}{\partial y}+\frac{\partial \bar{\nu}}{\partial x}\right)\right. \\
& \left.\left(\frac{\partial \bar{u}}{\partial z}+\frac{\partial \bar{w}}{\partial x}\right)\left(\frac{\partial \bar{\nu}}{\partial z}+\frac{\partial \bar{w}}{\partial y}\right)\right\}^{T} .
\end{aligned}
$$

The modal analysis is performed using this model, and the natural frequency and mode shapes specified are further utilized to obtain the desired acoustic responses. The in-vacuo modes of the vibrating structure can be obtained by finding the solution to the following eigenvalue equation:

$$
\left([K]-\omega^{2}[M]\right)\{\Phi\}=0,
$$

where $[K]$ is the stiffness matrix, $[M]$ is the mass 
matrix, $\omega$ is the circular frequency of vibration, and $\{\Phi\}$ is the eigenvector corresponding to the mode shape. The modal analysis is performed, and the mode shapes are extracted for each natural frequency of vibration. The nodal displacement vector for a mode, if normalized to the mass matrix, is regarded as the mode shape vector for that particular mode. Therefore, the mode shapes for any $i$ th mode can be obtained using the following relation:

$$
\left\{\Phi_{i}\right\}=\frac{\left\{U_{i}\right\}}{\sqrt{\left\{U_{i}\right\}^{T} M\left\{U_{i}\right\}}},
$$

where $\left\{U_{i}\right\}$ is the nodal displacement vector for the $i$ th mode.

The layered composite flat panel is subjected to a harmonic point excitation under different support conditions. The resulting structural vibrations cause disturbance in the surrounding acoustic medium. The methods adopted for computing the acoustic radiation caused by the vibrating plate are discussed in the following section.

\subsection{Acoustic modelling}

2.2.1. Conventional acoustic radiation mode theory A baffled vibrating laminated composite plate is considered for the present analysis. The origin of the coordinate system $(x, y$, and $z)$ lies at the centre of the structure placed in $x-y$ plane, as illustrated in Figure 2.

Sound pressure $p$ at any point on the plate can be written as a function of normal surface velocity, $\nu_{z}$, following the Rayleigh's integral formulation as below:

$$
p\left(r_{n}\right)=\frac{j \omega \rho}{2 \pi} \iint_{s} \nu_{z}\left(r_{m}\right) \frac{e^{-j k\left|r_{n}-r_{m}\right|}}{\left|r_{n}-r_{m}\right|} d S,
$$

where $k$ is the wavenumber $(\omega / c), c$ is the speed of sound in the surrounding fluid medium, $\rho$ is the density of the fluid medium, and $r_{i}$ is the position of any point in the laminated flat panel.

The discretization of the plate into elements (referred as radiators) and interpolation of the pressure and velocity over the elements allow the Rayleigh's

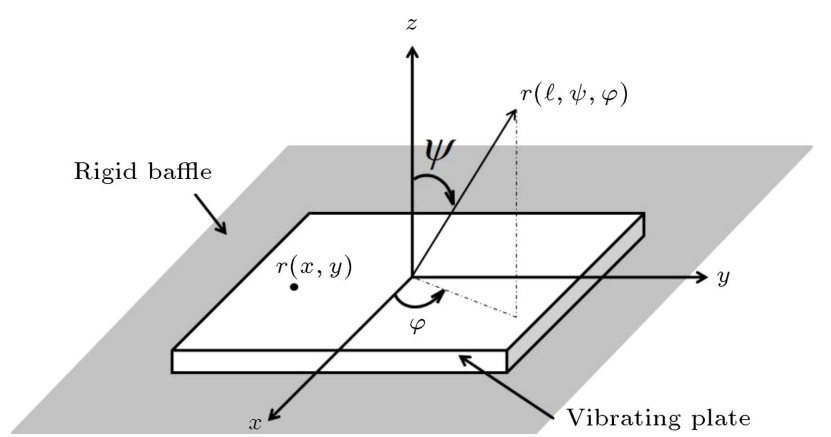

Figure 2. Vibrating plate lying in an infinite rigid baffle. integral (Eq. (6)) to be formulated in terms of surface pressure and nodal normal velocity as follows:

$$
p=[Z]\left\{\nu_{z}\right\},
$$

where $[Z]$ is the frequency-specific acoustic impedance matrix, $\{p\}$ and $\left\{\nu_{z}\right\}$ are the vectors containing nodal pressures and nodal normal velocities, respectively.

Sound power, $W$, radiated into the semi-infinite space above the plate is expressed as follows:

$$
W=\frac{1}{2} R_{e}\left[\iint_{s} p\left(r_{n}\right) \nu_{z}^{*}\left(r_{n}\right) d S\right]
$$

where symbol * indicates the complex conjugate.

Now, Eq. (8) can be further simplified as follows:

$$
W=\frac{S}{2} R_{e}\left[\nu_{z}{ }^{H} p\right]
$$

where $S$ is the surface area of each radiator, and superscript $H$ indicates the complex conjugate transpose.

Now, by substituting Eq. (7) into Eq. (9), the sound power radiated by the structure can be rewritten as follows:

$$
W=\frac{S}{2} R_{e}\left(\left\{\nu_{z}\right\}^{H}[\bar{Z}]\left\{\nu_{z}\right\}\right)
$$

where $[\bar{Z}]=\left(\int_{S}[N]^{T}[N] d S\right)[Z],[N]$ is the matrix of the interpolating functions. Matrix $[\bar{Z}]$ is symmetric based on the acoustic reciprocity principle [31].

Eq. (10) can be further simplified as follows:

$$
W=R_{e}\left(\left\{\nu_{z}\right\}^{H}[R]\left\{\nu_{z}\right\}\right)=\left\{\nu_{z}\right\}^{H}[R]\left\{\nu_{z}\right\} .
$$

Matrix $[R]=\frac{S}{2} R_{e}([\bar{Z}])$ is positive definite since the power output must be positive. Matrix $[R]$ is referred to as the radiation resistance matrix. Matrix $[R]$ is a real, symmetric and positive definite. Therefore, $[R]$ can be diagonalised using the eigenvalue decomposition steps expressed in the following form:

$$
[R]=Q \Lambda Q^{T}
$$

where $Q$, is the eigenvector matrix of $[R]$, and $\Lambda$ is the diagonal matrix containing the corresponding eigenvalue $\left(\lambda_{i}\right)$.

Now, by substituting $[R]$ into Eq. (11), the expression for $W$ is reduced to the following form [32]:

$$
\begin{gathered}
W=\left\{\nu_{z}\right\}^{H} Q \Lambda Q^{T}\left\{\nu_{z}\right\}=\left(Q^{T}\left\{\nu_{z}\right\}\right)^{H} \Lambda\left(Q^{T}\left\{\nu_{z}\right\}\right) \\
=y^{H} \Lambda y=\sum_{i=1}^{N R}\left|y_{i}\right|^{2} \lambda_{i},
\end{gathered}
$$

where $N R$ is the number of radiators. It is clear that 
the number of modes used in determining the acoustic power is equal to that of radiators on the surface of the element.

The plausible distribution of velocity over the surface of the radiator, represented by the eigenvectors, $Q_{k}$, is referred to as the radiation mode shape. Therefore, the radiation modes represent a potential acoustic radiation pattern on the radiator surface. However, the radiation modes are frequency and geometry dependent, yet independent of the material characteristics of the radiator [23].

The $k$ th surface velocity vector of the radiator is transformed with the corresponding acoustic radiation mode shape to obtain the radiation mode amplitude given by:

$$
y_{k}=Q_{k}^{T} \nu_{z}
$$

The radiation efficiency is defined as the capability of a structure to radiate sounds that can be expressed as follows:

$$
\sigma=\frac{W}{\rho c S_{T}\left\langle\bar{\nu}_{z}^{2}\right\rangle}
$$

where $S_{T}$ is the total surface area of the vibrating structure, and $\left\langle\bar{\nu}_{z}^{2}\right\rangle$ represents the average mean-square velocity defined as [32]:

$$
\left\langle\bar{\nu}_{z}^{2}\right\rangle=\frac{1}{2 S_{T}} \int\left|\nu_{z}^{2}\right| d S
$$

The formulations of the acoustic response indicators given by Eqs. (11) and (15) do not incorporate the vibration characteristics of the structure since matrix $[R]$ depends only on the wavenumber. Therefore, it is clear that these radiation modes depend only on the outer surface geometry of the radiating structure.

\subsubsection{Radiation efficiency and radiated sound power in terms of structural modes}

In order to reflect the effect of changes in structural behaviour on the acoustic radiation emitted by the vibrating structure in the surrounding medium, it is essential to formulate the radiation efficiency and sound power in terms of certain characteristics of the structure. The nodal surface velocity vector of the vibrating laminated plate can be represented in terms of structural modes as follows:

$$
\nu_{z}=\Phi_{n} \Omega_{n}
$$

where $\Phi_{n}$ represents the eigenvector corresponding to the $n$th structural mode, and $\Omega_{n}$ represents the corresponding modal coefficient vector expressed as [9]:

$$
\Omega_{n}=\frac{\Phi_{n}\left(\chi_{e}\right)}{m_{n}\left[\omega_{n}^{2}\left(1+j \eta_{n}\right)-\omega_{e}^{2}\right]},
$$

where $\chi_{e}$ is the excitation location on the vibrating plate, $\omega_{n}$ is the $n$th natural frequency, $\omega_{e}$ is the excitation frequency, $m_{n}$ is the modal mass (equal to 1 if $\Phi_{n}$ is mass normalized), and $\eta_{n}$ is the modal damping. It is important to mention that $\Phi$ is the real orthonormal matrix, i.e., $\Phi^{H}=\Phi^{T}$.

Now, by using Eq. (17) into Eq. (11), the acoustic power can be expressed as follows:

$$
W=\Omega^{H} \Phi^{H}[R] \Phi \Omega=\Omega^{H} M \Omega,
$$

where $M=\Phi^{H}[R] \Phi$ and, for any non-zero $\Omega$ value, $M$ is positive definite.

The eigenvalue decomposition of $M$ gives:

$$
M=P^{H} \Sigma P,
$$

where each column of $P$ contains an eigenvector of $M$, and each diagonal element of $\Sigma$ contains the corresponding eigenvalue $\left(z_{i}\right)$.

Now, Eq. (19) can be reformulated as follows:

$$
W=\Omega^{H}\left[P^{H} \Sigma P\right] \Omega=z^{H} \Sigma z=\sum_{n=1}^{N_{s}}\left|z_{n}\right|^{2} \gamma_{n}=\gamma_{n n}\left|z_{n}\right|^{2},
$$

where $\gamma=[P \Omega]^{H}, \gamma_{n n}$ is the $n$th element on the main diagonal of matrix $\sum$, and $N_{s}$ is the number of structural modes. It is essential to choose an appropriate value of $N_{s}$ in order to approximate sound power accurately. Usually, the number of structural modes is less than that of acoustic modes $\left(N_{s}<<N R\right)$, demonstrating less computational expense charged for the sound radiation using structural modes, as compared to acoustic radiation modes.

The $n$th modal mean square velocity, in terms of the structural modes, is written as follows:

$$
\begin{aligned}
\left\langle\bar{\nu}_{z, n}^{2}\right\rangle & =\frac{1}{2 S_{T}} \int\left|\Phi_{n}(x, y) z_{n}\right|^{2} d S \\
& =\frac{1}{2 S_{T}} \int\left|\Phi_{n}(x, y)\right|^{2} d S\left|z_{n}\right|^{2}=D_{n}\left|z_{n}\right|^{2},
\end{aligned}
$$

where $D_{n}=\frac{1}{2 S_{T}} \int\left|\Phi_{n}(x, y)\right|^{2} d S$.

Now, by substituting Eq. (22) into Eq. (15), the $n$th modal radiation efficiency (also referred to as selfradiation efficiency) is given as [32]:

$$
\sigma_{n n}=\frac{D_{n}}{\rho c S_{T}} \gamma_{n n}
$$

The radiated sound power can be obtained by considering either only the self-radiation efficiency term (reduced radiated sound power) or both of the selfand mutual-radiation efficiency terms (exact radiated sound power). Since all of the structural modes contribute to the acoustic radiation, it is more sensible to consider both the coupled (mutual) and uncoupled (self) modes to compute the exact sound power to 
Table 1. Material properties of the laminated composite flat panel [33,34].

\begin{tabular}{|c|c|c|c|c|c|c|}
\hline & \multicolumn{6}{|c|}{ Type of material } \\
\hline & \multicolumn{3}{|c|}{ CFRP } & \multicolumn{3}{|c|}{ GFRP } \\
\hline & $\begin{array}{c}\text { Material-1 } \\
\text { (M1) }\end{array}$ & $\begin{array}{c}\text { Material-2 } \\
\text { (M2) }\end{array}$ & $\begin{array}{c}\text { Material-3 } \\
\text { (M3) }\end{array}$ & $\begin{array}{c}\text { Material-4 } \\
\text { (M4) }\end{array}$ & $\begin{array}{c}\text { Material-5 } \\
\text { (M5) }\end{array}$ & $\begin{array}{c}\text { Material-6 } \\
\text { (M6) }\end{array}$ \\
\hline $\begin{array}{c}\text { Lamination } \\
\text { scheme }\end{array}$ & {$\left[45^{\circ} /-45^{\circ}\right]$} & {$\left[45^{\circ} /-45^{\circ}\right] \mathrm{s}$} & {$\left[0^{\circ} / 90^{\circ}\right] \mathrm{s}$} & {$\left[45^{\circ} /-45^{\circ}\right]$} & {$\left[45^{\circ} /-45^{\circ}\right] \mathrm{s}$} & {$\left[0^{\circ} / 90^{\circ}\right] \mathrm{s}$} \\
\hline$E_{1}$ & $6.695 \mathrm{GPa}$ & $6.469 \mathrm{GPa}$ & $12.34 \mathrm{GPa}$ & $4.669 \mathrm{GPa}$ & $4.408 \mathrm{GPa}$ & $5.639 \mathrm{GPa}$ \\
\hline$E_{2}=E_{3}$ & $6.314 \mathrm{GPa}$ & $5.626 \mathrm{GPa}$ & $10.45 \mathrm{GPa}$ & $4.351 \mathrm{GPa}$ & $4.081 \mathrm{GPa}$ & $4.926 \mathrm{GPa}$ \\
\hline$G_{12}=G_{13}$ & $2.700 \mathrm{GPa}$ & $2.050 \mathrm{GPa}$ & $6.450 \mathrm{GPa}$ & $3.250 \mathrm{GPa}$ & $1.100 \mathrm{GPa}$ & $0.750 \mathrm{GPa}$ \\
\hline$G_{23}$ & $1.350 \mathrm{GPa}$ & $1.025 \mathrm{GPa}$ & $3.225 \mathrm{GPa}$ & $1.625 \mathrm{GPa}$ & $0.550 \mathrm{GPa}$ & $0.375 \mathrm{GPa}$ \\
\hline$\nu_{12}=\nu_{23}=\nu_{13}$ & 0.3 & 0.3 & 0.3 & 0.17 & 0.17 & 0.17 \\
\hline$\rho$ & $1388 \mathrm{~kg} / \mathrm{m}^{3}$ & $1388 \mathrm{~kg} / \mathrm{m}^{3}$ & $1388 \mathrm{~kg} / \mathrm{m}^{3}$ & $1900 \mathrm{~kg} / \mathrm{m}^{3}$ & $1900 \mathrm{~kg} / \mathrm{m}^{3}$ & $1900 \mathrm{~kg} / \mathrm{m}^{3}$ \\
\hline
\end{tabular}

evaluate the sound radiation. However, in the lowfrequency range, the coupling between the radiating modes is weak, and the first radiation mode is the most dominant. Thus, curbing the first radiation mode in itself will lead to low acoustic radiation. In addition, the difference between the exact sound power and the sound power obtained by considering only the uncoupled modes is negligible owing to the weak coupling between the modes. Therefore, in the low frequency range, the uncoupled sound power could be used very well to express the acoustic radiation from a structure.

\section{Results and discussion}

The vibro-acoustic characteristics of the layered composite flat panels are studied in view of the structuredependent radiation modes. The solution to the eigenvalue problem, posed by Eq. (4), is obtained via the current simulation (ANSYS) model and is validated with the numerical results available in the published literature. The efficacy of the current simulation model has been strengthened by matching the present responses with the results obtained via new experimentation (modal analysis). In addition to this, the first radiation mode's amplitudes are computed using Rayleigh's integral and validated with the available numerical results. An in-house MATLAB code has been established on the developed acoustic formulation to compute the desired acoustic responses. The effects of composite material properties, constraint conditions, and harmonic point load location on the acoustic radiation responses of the layered composite flat panel are studied in detail by considering the displacement and velocity responses, radiation effi- ciencies, and acoustic power as the acoustic response indicators.

In this study, two $\left(\left[ \pm 45^{\circ}\right]\right)$ and four $\left(\left(\left[ \pm 45^{\circ}\right]_{s}\right.\right.$, $\left.\left[{ }^{\circ} / 90^{\circ}\right]_{s}\right)$ layers of CFRP and GFRP composite plates $(100 \mathrm{~mm} \times 100 \mathrm{~mm} \times 2 \mathrm{~mm})$ are considered for the analysis purpose. The corresponding material properties considered for the computational purpose are listed in Table 1 [33,34]. The definitions of the constraints applied at the support in the present analysis are as follows:

(a) Clamped support condition (C-C-C-C):

$$
\begin{aligned}
& \mu_{0}=\gamma_{0}=\zeta_{0}=\eta_{x}=\eta_{y}=\eta_{z}=0 \text { at } x=0 \text { and } a \\
& y=0 \text { and } b .
\end{aligned}
$$

(b) Simply supported condition (S-S-S-S):

$$
\begin{aligned}
& \gamma_{0}=\zeta_{0}=\eta_{y}=\eta_{z}=0 \quad \text { at } \quad x=0 \text { and } a ; \\
& \mu_{0}=\zeta_{0}=\eta_{x}=\eta_{z}=0 \quad \text { at } \quad y=0 \text { and } b .
\end{aligned}
$$

(c) Cantilever support condition (C-F-F-F):

$$
\mu_{0}=\gamma_{0}=\zeta_{0}=\eta_{x}=\eta_{y}=\eta_{z}=0 \text { at } x=0 \text { only }
$$

\subsection{Convergence behaviour}

Firstly, the convergence behaviour of the current simulation model has been established. The first eigen-frequencies are obtained for different number of radiators (mesh divisions) on the panel surface by considering various material properties of the composite lamina under two different support conditions (C-C-C$\mathrm{C}$ and S-S-S-S) presented in Table 2. It is evident that the present results converge well with the increasing 
Table 2. Convergence study of the first natural frequency.

\begin{tabular}{cccccccc}
\hline & \multicolumn{5}{c}{ Natural frequency (Hz) } \\
\cline { 2 - 4 } Mesh size & \multicolumn{3}{c}{ CFRP (C-C-C-C) } & & \multicolumn{2}{c}{ GFRP (S-S-S-S) } \\
\cline { 2 - 4 } & {$\left[ \pm 45^{\circ}\right]$} & {$\left[ \pm 45^{\circ}\right]_{s}$} & {$\left[0^{\circ} / 90^{\circ}\right]_{s}$} & & {$\left[ \pm 45^{\circ}\right]$} & {$\left[ \pm 45^{\circ}\right]_{s}$} & {$\left[0^{\circ} / 90^{\circ}\right]_{s}$} \\
\hline $3 \times 3$ & 1019.4 & 948.99 & 1367.30 & & 314.29 & 301.57 & 284.39 \\
$6 \times 6$ & 797.59 & 748.27 & 1079.40 & & 290.37 & 280.67 & 264.86 \\
$10 \times 10$ & 765.39 & 718.85 & 1036.80 & & 285.55 & 276.38 & 260.85 \\
$14 \times 14$ & 757.05 & 711.21 & 1025.70 & & 284.25 & 275.21 & 259.76 \\
$18 \times 18$ & 752.71 & 707.21 & 1021.30 & & 283.71 & 274.73 & 259.31 \\
$22 \times 22$ & 751.98 & 706.55 & 1020.00 & & 283.55 & 274.59 & 259.18 \\
$24 \times 24$ & 751.44 & 706.04 & 1018.30 & & 283.35 & 274.40 & 259.01 \\
\hline
\end{tabular}

Table 3. Validation of natural frequency.

\begin{tabular}{|c|c|c|c|c|c|c|c|c|c|}
\hline \multirow[b]{2}{*}{ Lay-up } & \multicolumn{9}{|c|}{ Natural frequency $(\mathrm{Hz})$} \\
\hline & Mode & 1 & 2 & 3 & 4 & 5 & 6 & 7 & 8 \\
\hline \multirow{3}{*}[\pm15^{\circ}]{$_{8}$} & Present & 93.75 & 209.99 & 258.53 & 376.62 & 407.11 & 538.78 & 574.41 & 656.58 \\
\hline & Ref. [23] & 96.30 & 187 & 278 & 327 & 383 & 520 & 538 & 557 \\
\hline & Diff. (\%) & -2.723 & 10.948 & -7.531 & 13.175 & 5.922 & 3.486 & 6.339 & 15.166 \\
\hline \multirow{3}{*}[\pm30^{\circ}]{$_{8}$} & Present & 121.59 & 273.99 & 296.57 & 487.77 & 512.11 & 577 & 758.26 & 795.21 \\
\hline & Ref. [23] & 127 & 291 & 301 & 507 & 544 & 571 & 790 & 806 \\
\hline & Diff. $(\%)$ & -4.449 & -6.208 & -1.494 & -3.942 & -6.227 & 1.040 & -4.186 & -1.357 \\
\hline \multirow{3}{*}[\pm45^{\circ}]{$_{8}$} & Present & 143.31 & 272.78 & 402.45 & 457.99 & 574.36 & 709.08 & 810.48 & 830.17 \\
\hline & Ref. [23] & 152 & 288 & 427 & 480 & 604 & 735 & 844 & 876 \\
\hline & Diff. (\%) & -6.064 & -5.580 & -6.100 & -4.806 & -5.161 & -3.655 & -4.136 & -5.521 \\
\hline \multirow{3}{*}[0/90^{\circ}]{$_{8}$} & Present & 121.90 & 215.58 & 418.02 & 441.23 & 489.69 & 624.82 & 725.81 & 879.37 \\
\hline & Ref. [23] & 130 & 230 & 442 & 470 & 522 & 661 & 756 & 793 \\
\hline & Diff. $(\%)$ & -6.645 & -6.689 & -5.737 & -6.520 & -6.598 & -5.790 & -4.159 & 9.822 \\
\hline
\end{tabular}

number of radiators on the surface (mesh refinement). In accordance with the rule of thumb for the acoustic analysis of structures [6,28], six elements per unit wavelength must be used to predict the responses accurately. Therefore, based on the results of the convergence test, a $(16 \times 16)$ mesh is utilized to compute the vibration responses throughout the present analysis.

\subsection{Validation studies}

The efficacy of the present scheme is established through different comparison studies presented in this section. For the validation of the structural and acoustic models, the natural frequencies of different modes and the first radiation mode's amplitude of the vibrating plate are obtained and compared with the benchmark results available in the published literature. In order to strengthen the confidence in the present simulation model, the responses obtained from the modal analysis are additionally compared with the specific results obtained through lab scale in-house experimentations.

\subsubsection{Validation of natural frequency}

Table 3 demonstrates the natural frequencies of the first eight modes for the 16-layered simply supported laminated composite plate with four different lamination schemes and the results of $\mathrm{Wu}$ and Huang [23]. The geometrical parameters $(a=0.40 \mathrm{~m}, b=$ 
$0.25 \mathrm{~m})$, material properties $\left(E_{1}=181 \mathrm{GPa}, E_{2}=\right.$ $\left.10.3 \mathrm{GPa}, G_{12}=7.17 \mathrm{GPa}, \nu_{12}=0.28\right)$, and the excitation loading (harmonic point load of $10 \mathrm{~N}$ at $(a / 2, b / 2))$ are taken to be the same as those [23]. It is evident that the results of the present simulation are closely in agreement with the published numerical results.

\subsubsection{Experimental validation of natural frequency}

In this section, the natural frequencies of the cantilever laminated composite plate are determined experimentally, and the results are compared with those obtained using the present simulation (ANSYS) model. The material properties of glass/epoxy composite plate are evaluated experimentally on three different specimens using the unidirectional tensile test through Universal Testing Machine (UTM) (INSTRON 1195) at National Institute of Technology (NIT), Rourkela, and listed in Table 4. For the experimental purpose, composite plate specimens with their corresponding lamination schemes are prepared by following the ASTM standard (D 3039/D 3039M). The experimental setup used for obtaining the free vibration responses of the plate (modal analysis) is depicted in Figure 3(a). The plate (3) subjected to cantilever (C-F-F-F) support condition through the support fixture (5) is excited by an impact hammer (6). The accelerometer (4) mounted on the plate captures the acceleration response of the plate. The PXIe (1) connects the accelerometer to LABVIEW and converts the acquired analog signal form into the digital signal form using an ingrained Analog to Digital (AD) converter. Subsequently, the output from the $\mathrm{AD}$ converter is processed in LABVIEW in accordance with the block diagram depicted in Figure 3(b). The values of the frequencies from the experiment and the corresponding values obtained from the present simulation model are listed in Table 5 . It is clearly seen that the responses obtained using simulation model are as good as the experimental values. It is worth noting that the present values of the frequencies are higher for

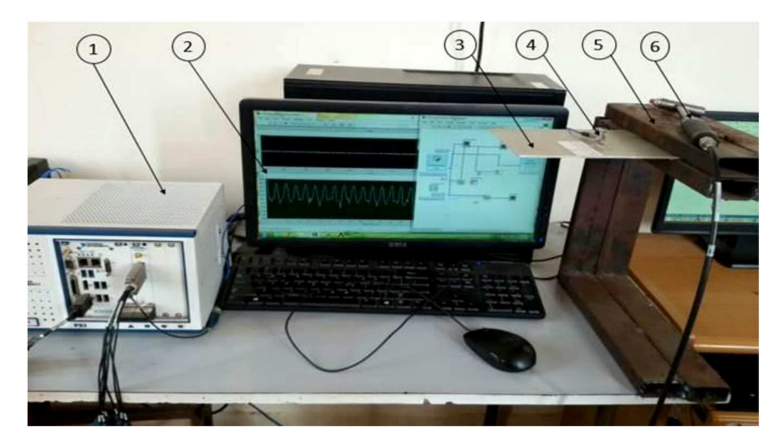

1. NI PXIe 1071 2. Computer screen 3. Laminated composite plate 4. Accelerometer 5. Fixture

(a)

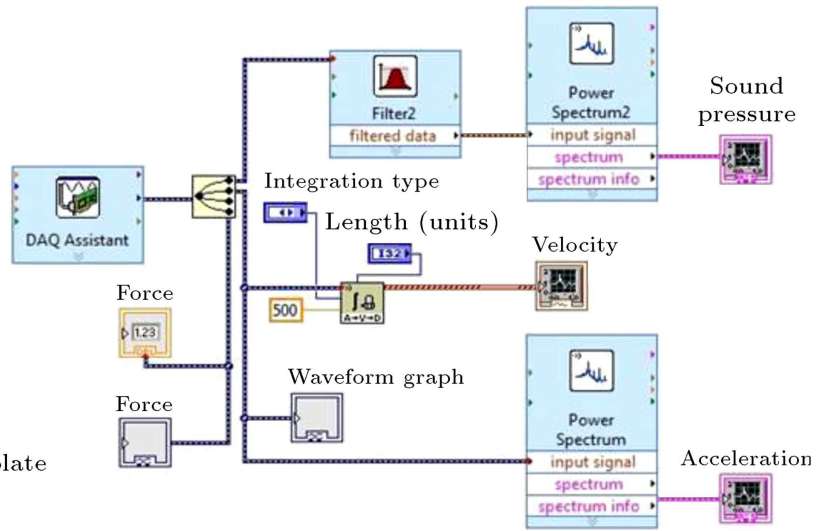

(b)

Figure 3. (a) Experimental setup. (b) Block diagram designed in LABVIEW for experimental data recording.

Table 4. Experimental material properties of the glass/epoxy composite lamina.

\begin{tabular}{ccc}
\hline Type of material & Material: ME1 & Material: ME2 \\
\hline Dimensions & $0.15 \mathrm{~m} \times 0.15 \mathrm{~m} \times 0.0016 \mathrm{~m}$ & $0.15 \mathrm{~m} \times 0.15 \mathrm{~m} \times 0.002 \mathrm{~m}$ \\
Lamination scheme & {$\left[0^{\circ} / 90^{\circ} / 90^{\circ} / 0^{\circ}\right]_{2}$} & {$\left[0^{\circ} / 9^{\circ} 0 / 90^{\circ} / 0^{\circ} / 0^{\circ} / 90^{\circ}\right]$} \\
$E_{1}$ & $6.125 \mathrm{GPa}$ & $7.205 \mathrm{GPa}$ \\
$E_{2}=E_{3}$ & $5.421 \mathrm{GPa}$ & $6.327 \mathrm{GPa}$ \\
$G_{12}=G_{13}$ & $2.790 \mathrm{GPa}$ & $2.800 \mathrm{GPa}$ \\
$G_{23}$ & $1.395 \mathrm{GPa}$ & $1.400 \mathrm{GPa}$ \\
$\nu_{12}=\nu_{23}=\nu_{13}$ & 0.17 & 0.17 \\
$\rho$ & $1400 \mathrm{~kg} / \mathrm{m}^{3}$ & $1420.05 \mathrm{~kg} / \mathrm{m}^{3}$ \\
\hline
\end{tabular}


Table 5. Comparison of natural frequencies of glass/epoxy laminated composite cantilever (C-F-F-F) plates with the experimental results.

\begin{tabular}{|c|c|c|c|c|}
\hline & \multicolumn{4}{|c|}{ Natural frequency $(\mathrm{Hz})$} \\
\hline & Material & : ME1 & Material: & ME2 \\
\hline Mode & Present Exp & erimental & Present Expe & erimental \\
\hline 1 & 23.696 & 21 & 31.643 & 26 \\
\hline 2 & 63.809 & 61 & 80.804 & 60 \\
\hline 3 & 148.99 & 140 & 198.75 & 174 \\
\hline 4 & 192.44 & 193.5 & 252.56 & 255 \\
\hline 5 & 228.93 & 228 & 295.55 & 290 \\
\hline 6 & 403.5 & 497 & 516.09 & 515 \\
\hline
\end{tabular}

material ME2, as compared to the material ME1, owing to the reduction in stiffness due to the less number of layers in ME2.

\subsubsection{Validation of acoustic properties: First radiation mode's amplitude}

The first radiation mode's amplitudes for a 16-layered anti-symmetric angle-ply $\left(\left[ \pm 45^{\circ}\right]_{8}\right)$ flat panel subjected to S-S-S-S support condition have been computed for two different damping ratios (0.1 and 0.2$)$ and compared with those available in $\mathrm{Wu}$ and Huang [23]. Figure 4(a) shows the comparison of the first radiation mode's amplitude for damping coefficient 0.1 . It is evident that the present results are in close agreement with the reference values. The small differences exist between the present and reference results due to the different theories employed for the estimation of surface velocities of the vibrating structure. It should be noted that the layer-wise FEM has been used in [23] (resemblance to the $3 \mathrm{D}$ elasticity solution), whereas the FSDT kinematic model has been adopted in the present case to compute the desired responses. The agreement between the results is excellent for damping ratio 0.2 , which is evident from Figure $4(\mathrm{~b})$.

\subsection{Additional illustrations}

The convergence and validation studies demonstrate the proficiency of the present scheme in easily obtaining vibro-acoustic responses of the layered composite flat panel with adequate accuracy. Some new illustrations are presented in this section to bring out the quantitative understanding of the acoustic responses of the layered composite flat panels. The displacement and velocity responses, radiation efficiencies, and sound power are considered as the acoustic parameter indicators. To compute the acoustic responses, twolayered and four-layered CFRP and GFRP composite flat panels are considered under C-C-C-C and S-S-S-S boundary conditions, respectively, and the plates are excited with a harmonic point load of $1 \mathrm{~N}$. In each illustration, two different loading cases are considered: Case 1 and Case 2. In Case 1, the load is applied at the central node $(a / 2, b / 2)$ where an anti-node is formed usually (Figure 5(a)), while, in Case 2, the load is applied at an eccentric node located at $(3 a / 4, b / 4)$ on the square plate to avoid any anti-node (Figure $5(\mathrm{~b}))$.

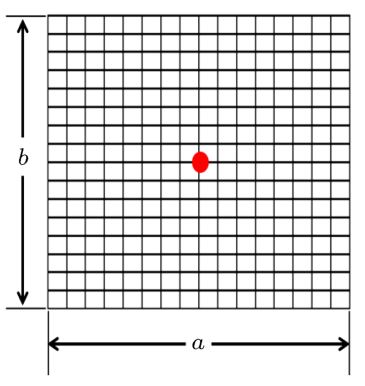

(a)

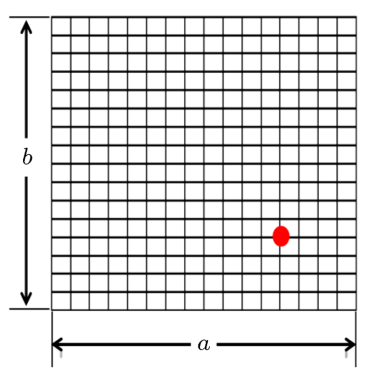

(b)
Figure 5. Different load cases: (a) Load Case 1, and (b) load Case 2.

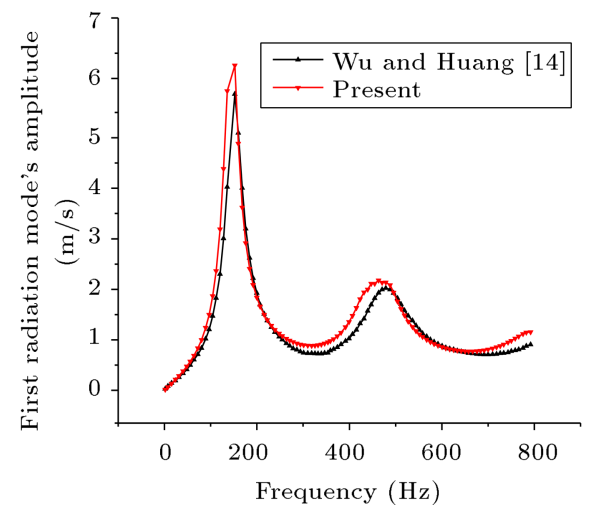

(a)

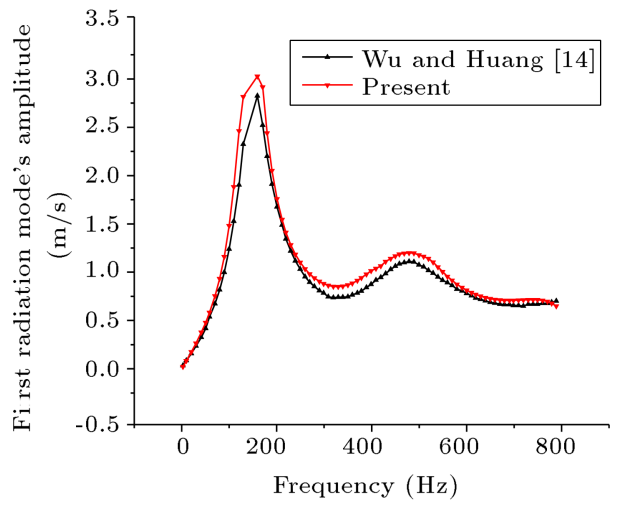

(b)

Figure 4. Comparison of the first radiation mode's amplitude: (a) Damping coefficient $=0.1$, and (b) damping coefficient $=0.2$. 


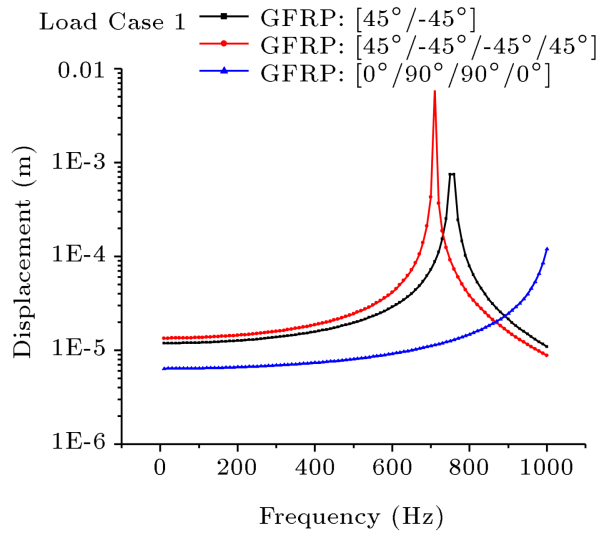

(a)

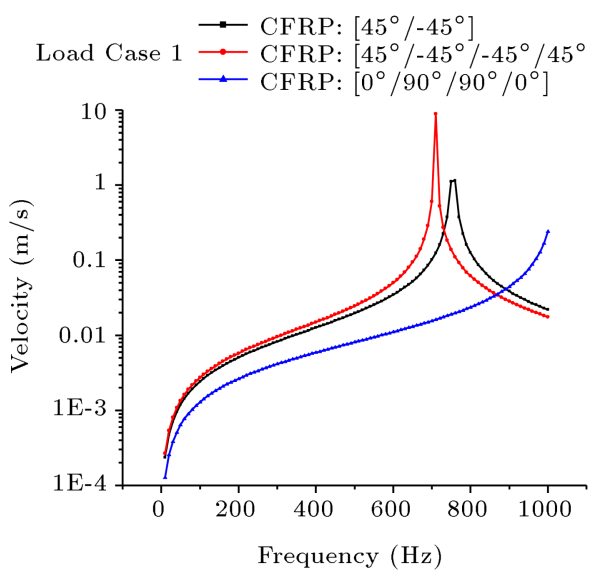

(c)

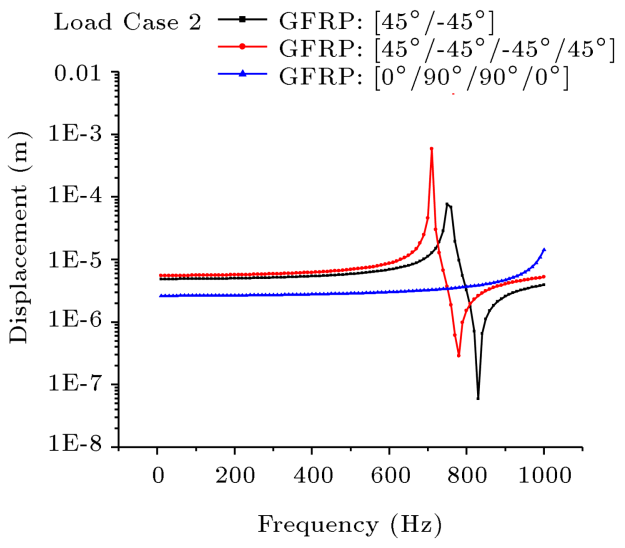

(b)

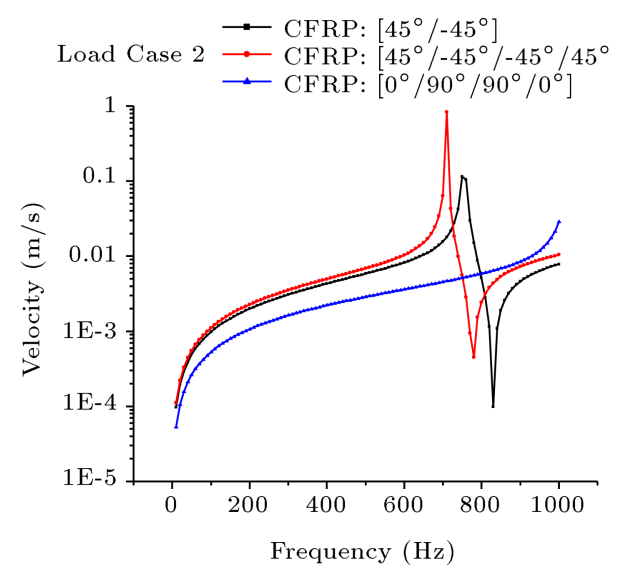

(d)

Figure 6. Displacement and velocity responses of clamped CFRP plates under different loading conditions.

\subsubsection{Displacement and velocity response}

It is well known that the radiated sound power depends on the displacement, velocity, and acceleration of the vibrating structure. The displacement and velocity responses of the point of excitation under different boundary and loading conditions for CFRP and GFRP flat panels are obtained using the present scheme and are shown in Figures 6 and 7 , respectively. It is evident from Figure 6(a) and (c) that the displacement and velocity are maximum for CFRP symmetric angleply laminate and minimum for the symmetric crossply laminate for all the frequencies in the range of operation. Based on Figure 6(b) and (d), a similar trend is observed for the second load case in the frequency range from $0-710 \mathrm{~Hz}$ to $790-1000 \mathrm{~Hz}$. For load Case 1, the velocity and displacement response of GFRP symmetric cross-ply laminate are more dominant in the frequency range of $0-510 \mathrm{~Hz}$, whereas the response of the angle-ply laminate is more dominant in $720-1000 \mathrm{~Hz}$ range; the same can be observed in Figure 7 (a) and (c). On the other hand, for load Case 2, it is noted that the two-layered GFRP angle-ply laminate $\left[45^{\circ} /-45^{\circ}\right]$ is the most suppressed one in $0-710 \mathrm{~Hz}$ range, as portrayed in Figure 7(b) and (d). The frequencydependent fluctuation in the behaviour of the vibrating plates can be attributed to the excitation of multiple modes when the load is placed at a node with zero displacement (which may occur in load Case 2), as compared to the excitation of a fewer modes or mostly a single mode when it is placed at an anti-node (as in load Case 1).

\subsubsection{Radiation efficiency}

It is clearly understood from Eq. (23) that the radiation efficiency defined in terms of structural modes solely depends on the frequency and mode shapes of the vibrating structure. The mode shapes are further dependent on the geometry and the number of constraints at the end support. Therefore, the radiation efficiency of a vibrating structure is independent of the location of the harmonic load. In this section, the self-radiation efficiencies of different modes are computed for the first type of loading (Case 1) only. The radiation efficiencies of clamped CFRP and simply supported GFRP composite flat panels are obtained using the present model, as shown in Figure 8 . In 


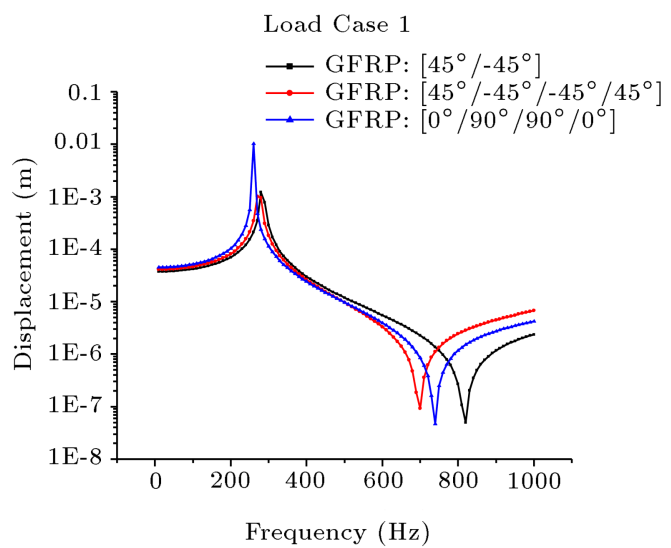

(a)

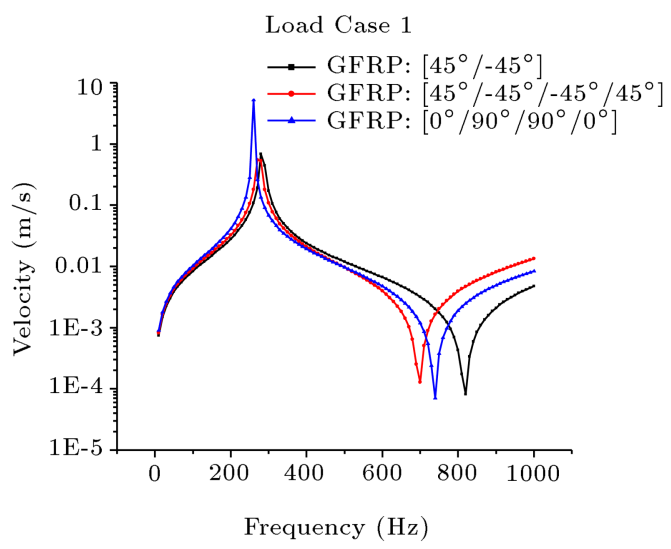

(c)

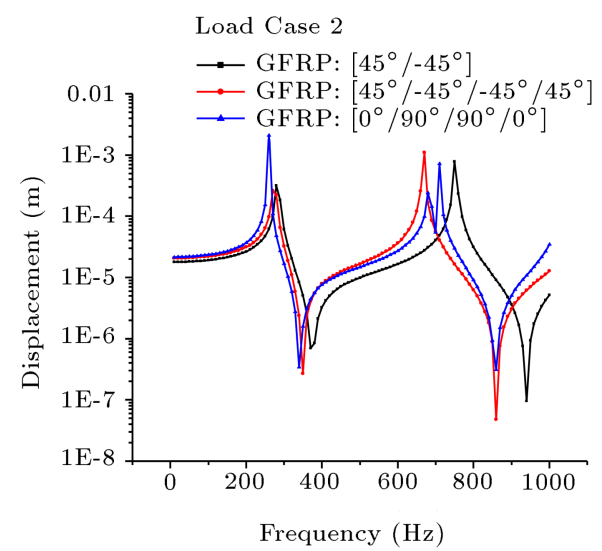

(b)

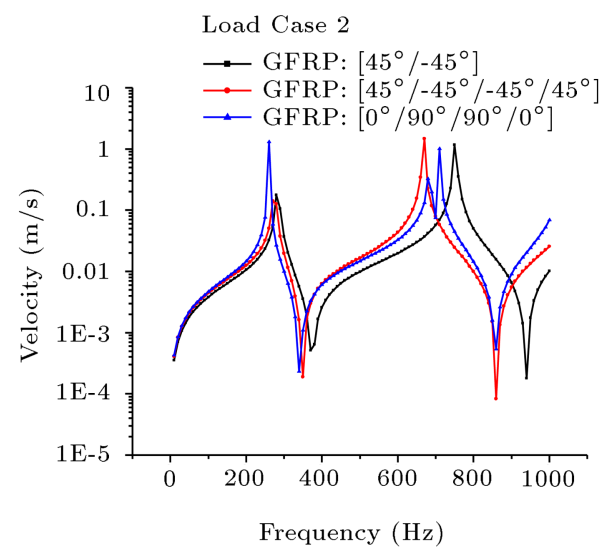

(d)

Figure 7. Displacement and velocity response of simply supported GFRP plates under different loading conditions.

order to observe the effect of coincidence frequency, the results are plotted for higher excitation frequency range (up to $25 \mathrm{kHz}$ ). It is observed that the radiation efficiencies of all the modes increase monotonically with increasing excitation frequency, and the first radiation mode $(1,1)$ has the highest efficiency for all the cases, irrespective of the type of material and support conditions. The radiation efficiency of the modes crosses unity after the first coincidence frequency of the plates and, thereafter, converges to unity for all higher frequencies. In addition to this, it is also noted that the radiation efficiency of odd modes is larger than that of any other modes for the low-frequency range. It is worth noting that the radiation efficiencies tend to converge towards a single value for the higher frequencies, implying that all the modes have a significant contribution towards the acoustic radiation for higher frequencies. However, the convergence rate of less efficient modes, such as $(1,4)$ and $(2,2)$, is higher than that of the relatively more efficient modes. This is an indication of the tendency of the weakly radiating modes to develop into strongly radiating modes at a faster rate corresponding to the higher excitation frequency. In addition, it is noted that the radiation patterns of the most efficient radiating modes $(1,1)$ and $(1,3)$ do not vary significantly with a lamination scheme.

\subsubsection{Radiated sound power}

The sound power $\left(\mathrm{dB}\right.$, reference $\left.=10^{-12} \mathrm{~W}\right)$ radiated by the vibrating clamped CFRP and simply supported GFRP composite plates is computed for two types of loading using the structural modes, shown in Figures 9 and 10, respectively. In each case, the responses are obtained by including both the un-coupled or selfradiation modes (reduced sound power) and all the radiation modes (exact sound power). It is obvious from Figure 9 that the location of the harmonic point load does not have much effect on the radiation pattern of the clamped CFRP plates. However, the magnitude of radiated power is less for load Case 2 than that for load Case 1. Further, the location of excitation force has a significant influence on the radiation pattern of the simply supported GFRP plate, as presented in Figure 10. It can be seen clearly that the differences between the exact and reduced sound powers are insignificant in particular for the clamped CFRP plates. This is attributed to the fact 


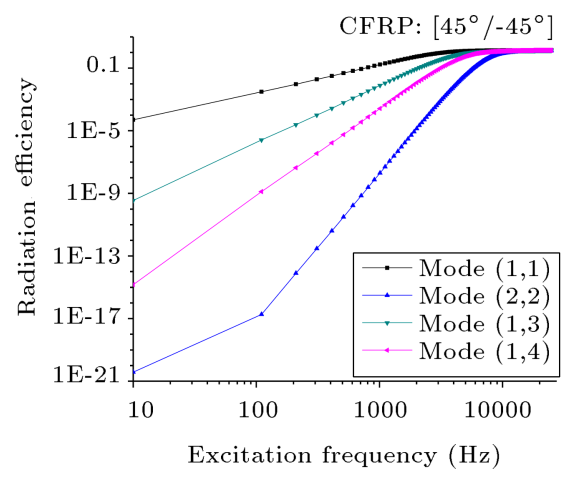

(a)

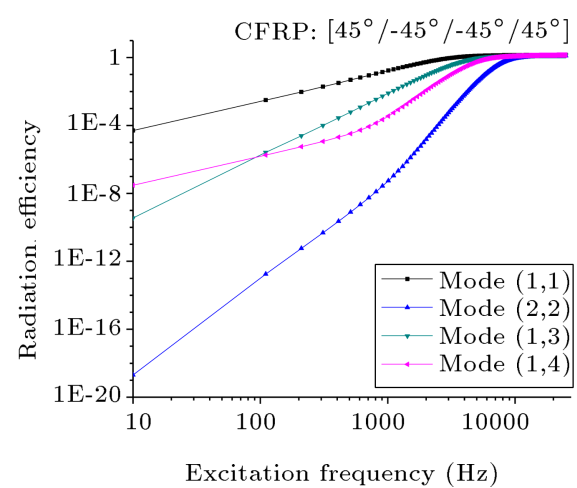

(b)

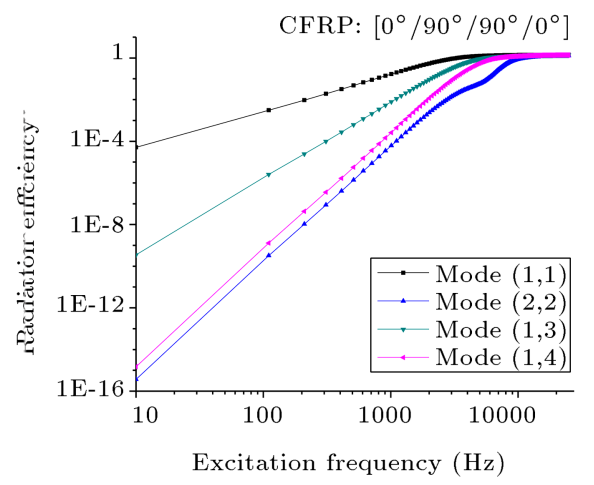

(c)

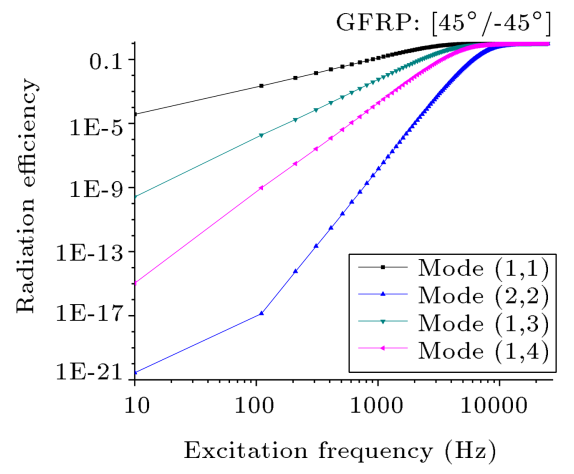

(d)

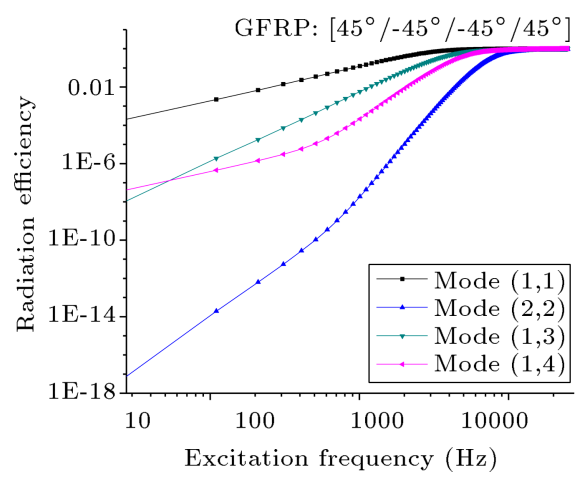

(e)

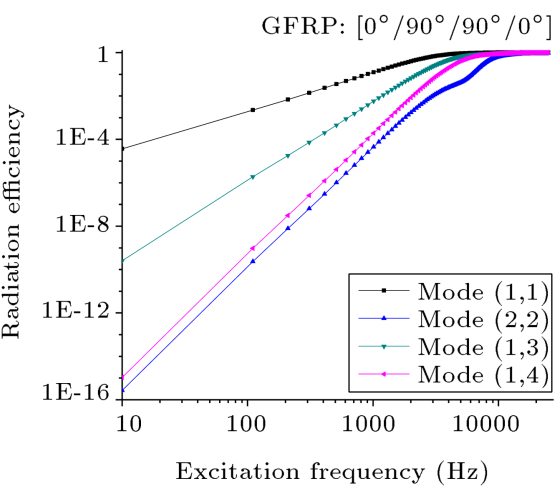

(f)

Figure 8. Self-radiation efficiencies of different modes for clamped CFRP ((a), (b) and (c)) and simply supported GFRP ((d), (e) and (f)) composite flat panel.

that the first structural radiation mode is the only dominant mode contributing to the sound power. The same is also evident from the analysis of radiation efficiencies of different modes, as presented in the previous section. However, it is worth noting that there exists an appreciable difference between the exact and reduced sound powers for the case of the simply supported GFRP plate corresponding to the higher excitation frequencies. It is also interesting to observe that, in the considered excitation frequency range and for each type of loading cases, the maximum radiated sound power is lower for cross-ply laminations and higher for angle-ply laminations in the case of CFRP composite plates. However, a reverse trend is noticed in the case of GFRP laminates.

\section{Conclusion}

The vibration frequency and acoustic radiation characteristics of the layered flat panel in an infinite rigid baffle under the harmonic point load were investigated in this article. Initially, the free vibration responses of the CFRP and GFRP laminated composite plates were obtained using the simulation model developed in ANSYS and compared with the available numerical and presented experimental results. In addition, the 


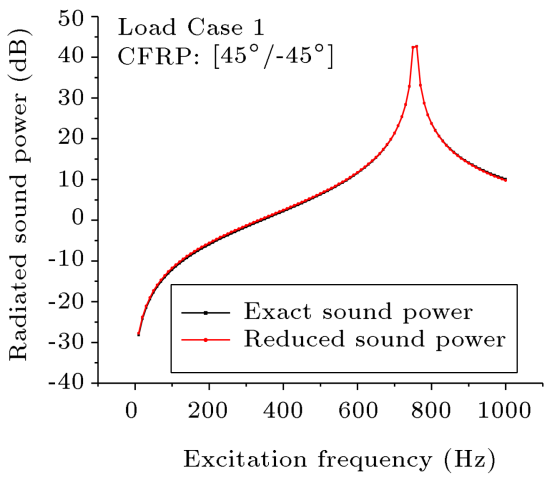

(a)

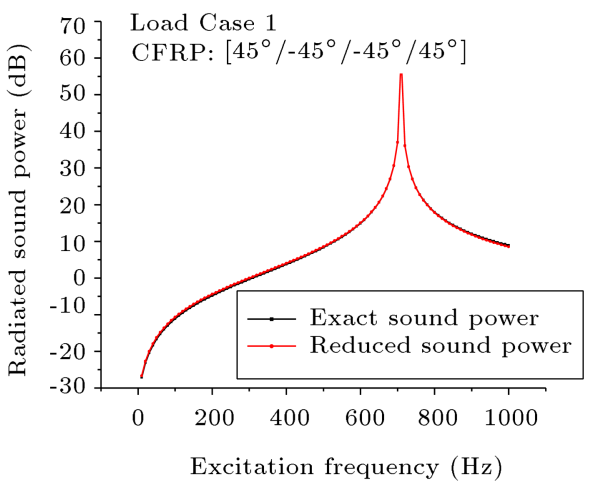

(b)

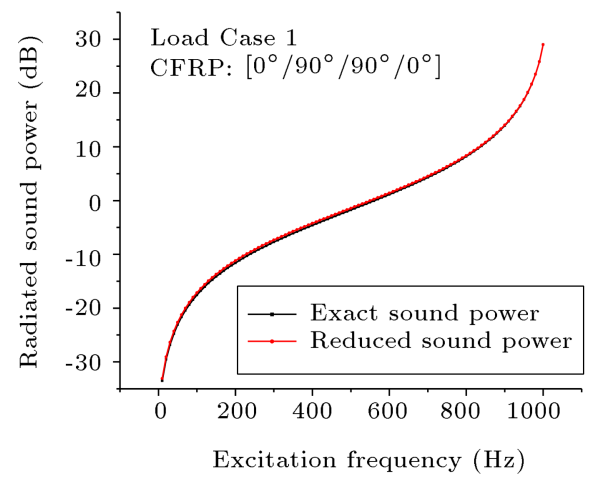

(c)

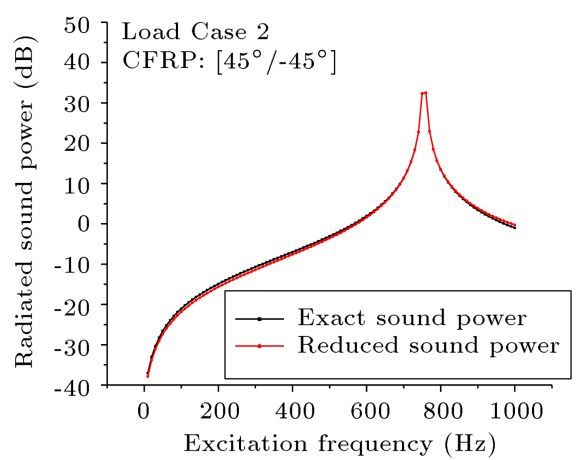

(d)

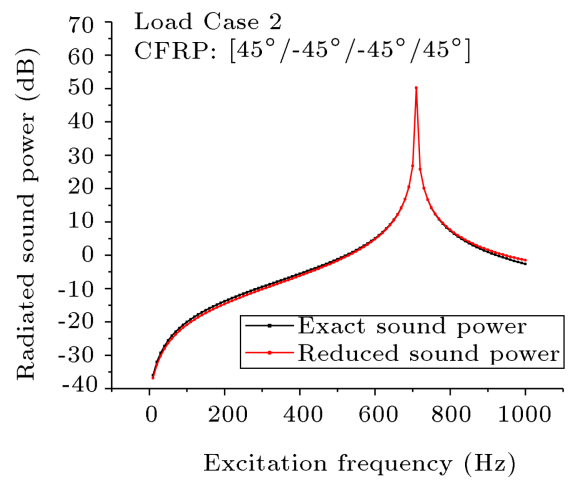

(e)

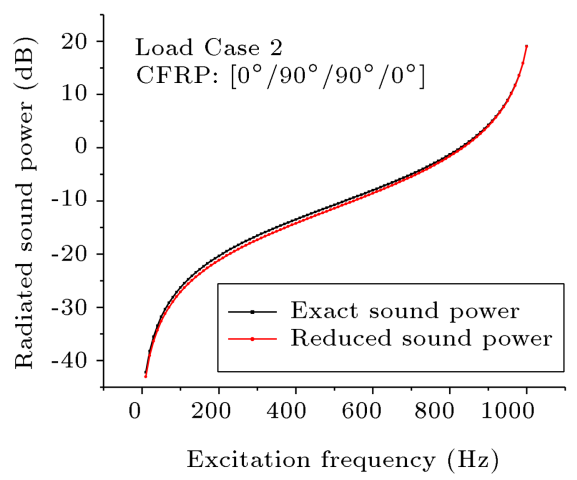

(f)

Figure 9. Radiated sound power for clamped CFRP composite flat panel under different loading conditions.

first radiation mode's amplitudes of the vibrating flat panels are computed (using an explicit relation between pressure and velocity) with the help of a computer code developed in MATLAB in conjunction with Rayleigh's integral formulation and compared with that of the benchmark results available in the published literature. Further, the velocity and displacement behaviour of the plate due to a point harmonic excitation were analysed to show the effect of the location of the point load, number of constraints at the support, and composite material properties on the acoustic radiation responses of the layered composite flat panel. The structural radiation modes (in contrast to the acoustic radiation modes) were utilized to evaluate the sound radiation from the vibrating plate. Based on the numerical illustration, it was observed that the location of the excitation force has no effect on the radiation efficiency. However, the first radiation mode's contribution to the acoustic radiation is the most significant and the other modes radiate weakly, thus not contributing much to the acoustic radiation in the considered frequency range. The exact acoustic power radiated by the vibrating plate was evaluated by all the terms used and compared with the reduced radiated acoustic power by considering the self-radiation terms only. Based on this analysis, it was observed that the difference between 


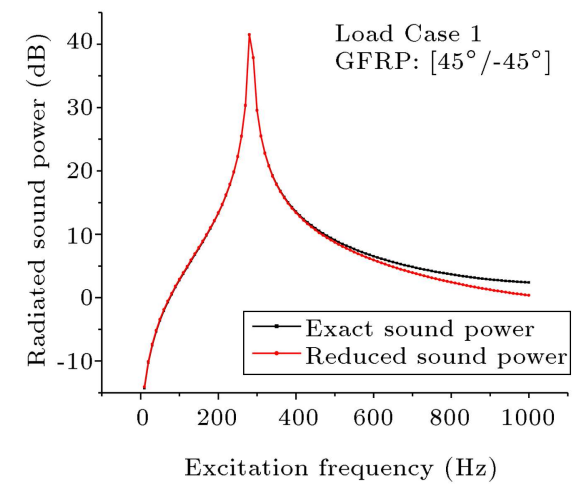

(a)

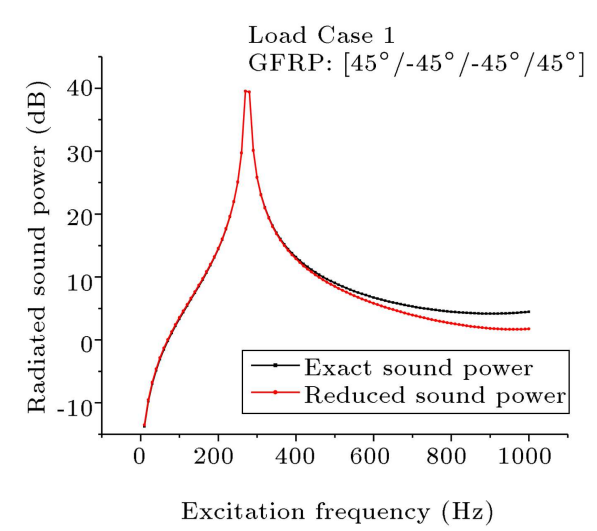

(b)

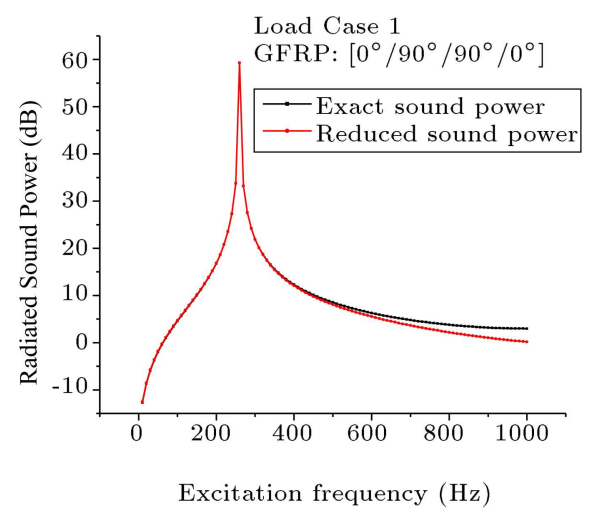

(c)

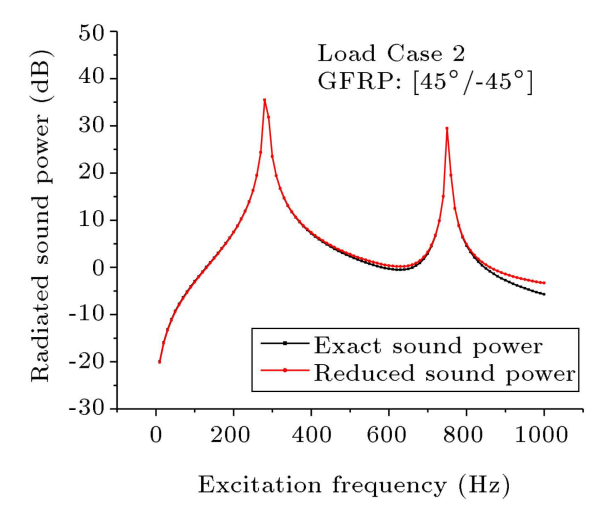

(d)

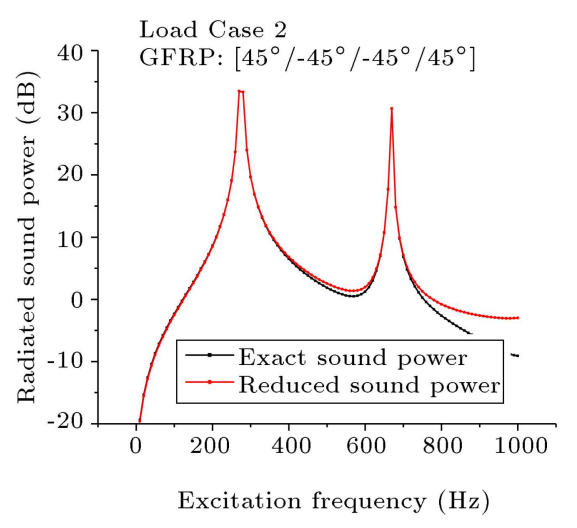

(e)

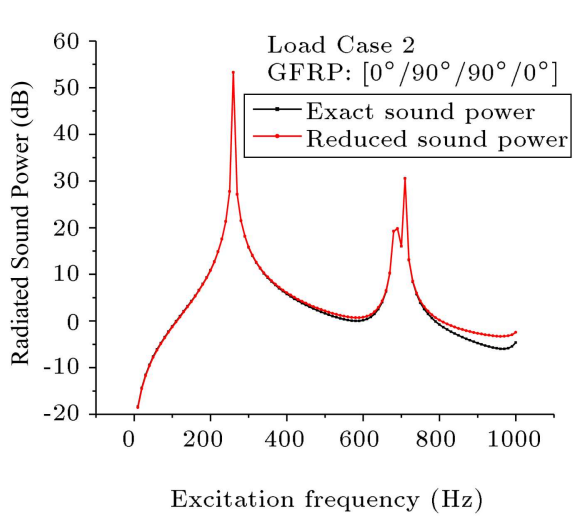

(f)

Figure 10. Radiated sound power for simply supported GFRP composite flat panel under different loading conditions.

the exact and reduced sound powers is insignificant for low excitation frequency ranges.

\section{References}

1. Cunefare, K.A. "The minimum multimodal radiation efficiency of baffled finite beams", J. Acoust. Soc. Am., 90(5), pp. 2521-2529 (1991).

2. Cunefare, K.A. and Currey, M.N. "On the exterior acoustic radiation modes of structures", J. Acoust. Soc. Am., 96(4), pp. 2302-2312 (1994).

3. Currey, M.N., Cunefare, K.A. "The radiation modes of baffled finite plates", The J. Acoust. Soc. Am., 98(3), pp. 1570-1580 (1995).

4. Sarkissian, A. "Acoustic radiation from finite structures", J. Acoust. Soc. Am., 90(1), pp. 574-578 (1991).

5. Naghshineh, K., Koopmann, G.H., and Belegundu, A.D. "Material tailoring of structures to achieve a minimum radiation condition", J. Acoust. Soc. Am., 92(2), pp. 841-855 (1992).

6. Li, S. and Li, X. "The effects of distributed masses on acoustic radiation behaviour of plates", Appl. Acoust., 69, pp. 272-279 (2008).

7. Yin, X. W., Gu, X. J., Cui, H. F., and Shen, R.Y. 
"Acoustic radiation from a laminated composite plate reinforced by doubly periodic parallel stiffeners", $J$. Sound Vib., 306, pp. 877-889 (2007).

8. Yin, X., and Cui, H.F. "Acoustic radiation from a laminated composite plate excited by longitudinal and transverse mechanical drives", J. Appl. Mech., 76(4), pp. 0044501 (2009).

9. Ji, L., and Bolton, J.S. "Sound power radiation from a vibrating structure in terms of structure-dependent radiation modes", J. Sound Vib., 335, pp. 245-260 (2015).

10. Putra, A. and Thompson, D.J. "Sound radiation from rectangular baffled and unbaffled plates", Appl. Acoust., 71(12), pp. 1113-1125 (2010).

11. Li, W.L. "An analytical solution for the self- and mutual radiation resistances of a rectangular plate", J. Sound Vib., 245(1), pp. 1-16 (2001).

12. Li, W.L. and Gibeling, H.J. "Determination of the mutual radiation resistances of a rectangular plate and their impact on the radiated sound power", J. Sound Vib., 229(5), pp. 1213-1233 (2000).

13. Reddy, J.N., Mechanics of Laminated Composite Plates and Shells: Theory and Analysis, 2nd Edn., CRC Press, Florida (2004).

14. Bellifa, H., Benrahou, K.H., Hadji, L., Houari, M.S.A., and Tounsi, A. "Bending and free vibration analysis of functionally graded plates using a simple shear deformation theory and the concept the neutral surface position", J. Braz. Soc. Mech. Sci. Eng., 38(1), pp. 265-275 (2016).

15. Bourada, M., Kaci, A., Houari, M.S.A., and Tounsi, A. "A new simple shear and normal deformations theory for functionally graded beams", Steel Compos. Struct., 18(2), pp. 409-423 (2015).

16. Houari, M.S.A., Tounsi, A., Bessaim, A., and Mahmoud, S.R. "A new simple three-unknown sinusoidal shear deformation theory for functionally graded plates", Steel Compos. Struct., 22(2), pp. 257- 276 (2016).

17. Mahi, A., Adda Bedia, E.A., and Tounsi, A. "A new hyperbolic shear deformation theory for bending and free vibration analysis of isotropic, functionally graded, sandwich and laminated composite plates", Appl. Math. Model., 39, pp. 2489-2508 (2015).

18. Chikh, A., Tounsi, A., Hebali, H., and Mahmoud, S.R. "Thermal buckling analysis of cross-ply laminated plates using a simplified HSDT", Smart Struct. Syst., 19(3), pp. 289-297 (2017).

19. Bouderba, B., Houari, M.S.A., Tounsi, A., and Mahmoud, S.R. "Thermal stability of functionally graded sandwich plates using a simple shear deformation theory", Struct. Eng. Mech., 58(3), pp. 397-422 (2016).

20. Ait Yahia, S., Ait Atmane, H., Houari, M.S.A., and Tounsi, A. "Wave propagation in functionally graded plates with porosities using various higher-order shear deformation plate theories", Struct. Eng. Mech., 53(6), pp. 1143-1165 (2015).
21. Draiche, K., Tounsi, A., and Mahmoud, S.R. "A refined theory with stretching effect for the flexure analysis of laminated composite plates", Geomech. Eng., 11(5), pp. 671-690 (2016).

22. Hamidi, A., Houari, M.S.A., Mahmoud, S.R., and Tounsi, A. "A sinusoidal plate theory with 5-unknowns and stretching effect for thermomechanical bending of functionally graded sandwich plates", Steel Compos. Struct., 18(1), pp. 235-253 (2015).

23. Wu, J. and Huang, L. "Natural frequencies and acoustic radiation mode amplitudes of laminated composite plates based on the layerwise FEM", Int. J. Acoust. Vib., 18(3), pp. 134-140 (2013).

24. Chandra, N., Raja, S., Nagendra Gopal, K.V. "Vibroacoustic response and sound transmission loss analysis of functionally graded plates", J. Sound Vib., 333, pp. 5786-5802 (2014).

25. Everstine, G.C., Henderson, F.M "Coupled finite element/boundary element approach for fluid-structure interaction", J. Acoust. Soc. Am., 87(5), pp. 1938-1947 (1990).

26. Jeyaraj, P. "Vibro-acoustic behavior of an isotropic plate with arbitrarily varying thickness", Eur. J. Mech. A. Solid., 29, pp. 1088-1094 (2010).

27. Jeyaraj, P., Ganesan, N., and Padmanabhan, C. "Vibration and acoustic response of a composite plate with inherent material damping in a thermal environment", J. Sound Vib., 320, pp. 322-338 (2009).

28. Jeyaraj, P., Padmanabhan, C., and Ganesan, N. "Vibro-acoustic behaviour of a multi-layered viscoelastic sandwich plate under a thermal environment", $J$. Sandw. Struct. Mater., 13(5), pp. 509-537 (2011).

29. Zhao, X., Geng, Q., and Li, Y. "Vibration and acoustic response of an orthotropic composite laminated plate in a hygroscopic environment", J. Acoust. Soc. Am., 133(3), pp. 1433-1442 (2013).

30. Au, F.T.K. and Wang, M.F. "Sound radiation from forced vibration of rectangular orthotropic plates under moving loads", J. Sound Vib. 281, pp. 1057-1075 (2005).

31. Arunkumar, M., Jeyaraj, P., Gangadharan, K.V., and Lenin Babu, M.C. "Influence of nature of core on vibro acoustic behaviour of sandwich aerospace structures", Aerosp. Sci. Technol., 56, pp. 155-167 (2016).

32. Mao, Q., Pietrzko, S., Control of Noise and Structural Vibration, Springer London (2013).

33. Sahoo, S.S., Singh, V.K., and Panda, S.K. "Nonlinear flexural analysis of shallow carbon/epoxy laminated composite curved panels: Experimental and numerical investigation", J. Eng. Mech., 142(4), 04016008-1-13 (2016) DOI: $10.1177 / 1464420715600191$.

34. Sahoo, S.S., Panda, S.K., and Mahapatra, T.R. "Static, free vibration and transient response of laminated composite curved shallow panel - An experimental approach", Eur. J. Mech. A. Solid., 59, pp. 95-113 (2016). 


\section{Biographies}

Nitin Sharma, the lead author of this article, is an Assistant Professor and currently pursuing his $\mathrm{PhD}$ as a faculty scholar at the School of Mechanical Engineering, KIIT University, Bhubaneswar, Odisha, India. He has received Master of Engineering degree from Tokyo Institute of Technology, Japan. He is now studying the vibro-acoustic behaviour of laminated composite structures under elevated environmental conditions as a part of his $\mathrm{PhD}$ work.

Trupti Ranjan Mahapatra is working currently as an Associate Professor at the Department of Production Engineering, Veer Surendra Sai University of Technology (VSSUT), Burla, 768018, Odisha, India. He has completed his PhD from KIIT University in the domain of the nonlinear bending and vibration of composite structures in hostile environment. He has $42 \mathrm{SCI}$ journal papers to his credit. His major research interest lies in nonlinear FEM, numerical/experimental nonlinear mechanical responses of composite structures/smart structures, FGMs. He is a member of Institution of Engineers, India and recently received the IEI Young Engineer Award-2016 and "COSMICYoung Scientist Award-2017".

Subrata Kumar Panda is an Assistant Professor at the National Institute of Technology (NIT), Rourkela, Odisha, India. He has completed his PhD from IIT, Kharagpur, India on the post-buckling behavior of composite structures. He has 76 SCI Journal papers, many conference papers and 1 patent to his credit. He is currently working on numerical and experimental analysis of smart composite and FGM structures, laminated/delaminated composite and FG-CNTs. He is also interested in the field of bio-mechanics. He has handled/handling four sponsored projects (AICTE, DST, DRDO, and BRNS) as PI. He recently received the COSMIC Outstanding Researcher Award-2017. 